\title{
CORRIGENDA (Volume 5)
}

In Rountree, P. M. (1951), J. gen. Microbiol. 5, 673-680.

On p. 673, line 6 of the SUmmary: adsorption occurred in distilled water should be no adsorption occurred in distilled water.

In Cutrs, N. S. \& Rainbow, C. (1951), J. gen. Microbiol. 5, 860-868.

On p. 864, Fig. 1 , the figures on the ordinates should be: $0.25,0.50,0.75,1.00$, 1.25 .

On p. 865 , Fig. 4, the figures 1.20 on the ordinate should be 1.00 .

In WARE, G. C. (1951), J. gen. Microbiol. 5, 880-884.

On p. 880, towards the end of the second line of MErHods: organic should be inorganic. 